\title{
LA CRISIS Y SUS RETOS PARA LA DEMOCRACIA. ¿HACIA UN NUEVO CONTRATO POLÍTICO Y SOCIAL?*
}

\author{
The crisis and its challenges for democracy. \\ Towards a new political and social contract?
}

\author{
Rafael Rubio Núñez \\ Profesor Titular de Derecho constitucional \\ Universidad Complutense de Madrid \\ rafa.rubio@cepc.es \\ doi: http://dx.doi.org/10.18543/ed-66(1)-2018pp215-233
}

Recibido: 17.04.2018

Aceptado: 25.06.2018

\section{Resumen}

Ante la percepción generalizada de crisis, y la interrelación entre sus distintos planos, se plantea la hipótesis de una crisis de origen únicamente económica, con una réplica o traslado al ámbito social y político.

Por otro lado, están aquellos que señalan que cada plano requiere de soluciones diferentes, y que soluciones económicas no llevan necesariamente a un fortalecimiento de la democracia, como se puede observar en un número creciente de países en los que la libertad de mercado, y sus buenos resultados conviven con regímenes autoritarios.

* Cómo citar / Citation 'Chicago-Deusto' (Autor-fecha / Author-date / Lista de referencias / Reference list entries): Rubio Núñez, Rafael. 2018. «La crisis y sus retos para la democracia. ¿Hacia un nuevo contrato político y social?». Estudios de Deusto 66, n. ${ }^{\circ} 1$ : 215-233. doi: http://dx.doi.org/10.18543/ed-66(1)-2018pp215-233.

Transcripción revisada de la ponencia pronunciada en el III Congreso Científico sobre el Derecho en Filipinas \& España. La globalización y el estado social: debates constitucionales actuales en Europa y Asia. Universidad de Málaga, Mayo, 2017. 
Este trabajo se centrará en el aspecto institucional, y concretamente, en la democracia. Así, se acabará concluyendo sobre los peligros de poner en la reforma constitucional las expectativas de solución de problemas económicos y sociales, y sobre la necesidad de trabajar para que se den condiciones que hagan posible la reforma.

\title{
Palabras clave
}

Crisis económica; crisis social; crisis política; crisis institucional; reforma constitucional.

\begin{abstract}
Given the general perception of crisis, and the interrelation between its different levels, the hypothesis of a crisis of solely economic origin is posed, with a replication or transfer to the social and political sphere.

On the other hand there are those who point out that each plane requires different solutions, and that economic solutions do not necessarily lead to a strengthening of democracy, as can be seen in a growing number of countries in which market freedom, and its good results coexist with authoritarian regimes.

This work will focus on the institutional aspect, and specifically, on democracy. Thus, it will end up concluding how the reform of the Constitution is not the solution of all social problems.
\end{abstract}

\section{Keywords}

Economic crisis; social crisis; political crisis; institutional crisis; constitutional reform. 
SuMARIO: I. LA NORMALIDAD DE LA CRISIS. II. CRISIS ECONÓMICA Y CRISIS SOCIAL. III. LA CRISIS POLÍTICA E INSTITUCIONAL. IV. LA REFORMA CONSTITUCIONAL Y OTRAS RESPUESTAS A LAS CRISIS.

\section{LA NORMALIDAD DE LA CRISIS}

Nuestra época está dominada por el concepto de crisis. Las noticias diarias están llenas de referencias a la misma, crisis económica, crisis de las instituciones, crisis de las familias, crisis de los emigrantes... No se sabe si es una consecuencia de una época en la que la información tiene algo de espectáculo o que realmente la inestabilidad se ha convertido en un componente inevitable de nuestra sociedad. La vida política es, en gran medida, una gestión continua de crisis.

Aunque es habitual acogerse a la versión china de la palabra crisis (Wei Ji), que señala ésta como una mezcla entre peligro y oportunidad, deberíamos mirar con más frecuencia al origen griego (de la palabra), el verbo derivado del griego krísis 'decisión', del verbo kríno 'yo decido, separo, juzgo' que apunta a investigar, valorar, juzgar, y decidir. Esta versión de la crisis nos sitúa en un tiempo de reflexión, un replanteamiento ante el tópico «cambio de paradigma» donde valorar lo esencial y construir sobre ello.

Aunque seguimos tan metidos de lleno en ella que para algunos podemos hablar de una crisis crónica, con la perspectiva que da el tiempo podemos decir que lo que empezó como una profunda crisis económica (que se manifestó en el año 2008), se ha trasladado a la vida social, en lo que algunos han denominado como la ruptura del contrato social por el que más allá de la crisis, se produce la ruptura de algunas de las garantías sociales que teníamos asumidas como permanentes. Esta crisis social no diagnosticada se traslada como consecuencia de esa ausencia de diagnosis a la vida política, primero como una crisis de liderazgos (que se marchen todos), y después como una crisis de las instituciones, incluido el propio concepto de democracia, llegando a cuestionar algo que desde la caída del muro, se consideraba parte intrínseca del «fin de la historia» tal y como lo definió Fukuyama (2015). Hoy es el propio autor norteamericano el que señala como estamos asistiendo al desmantelamiento de los pilares de la democracia liberal incluso por parte de líderes elegidos democráticamente ${ }^{1}$.

Este proceso de contagio no nos puede llevar a la confusión de planos. Aunque es indudable que están relacionados entre sí, no podemos obviar que

${ }^{1}$ Citado en Goodman, P. The Post-World War II Order is under assault from the powers that built it. The New York Times, 26.3.2018 
por tener causas diferentes, tienen también soluciones diferentes. Es por esto por lo que no podemos creer que una vez resuelta la crisis económica, ese efecto contagio propagará, sin más decisión que la espera o la mera contemplación, la solución entre las otras. Y aunque algunos creen que la crisis económica no es más que un paréntesis temporal en la historia del progreso que, desde finales del siglo XX, se intuía eterno, fruto de una ley histórica que no era tal, nosotros pensamos que estamos ante una crisis social de raíces más profundas, tanto que, como hemos visto, afecta al plano político e institucional y ante la que es necesario articular soluciones específicas en cada una de sus manifestaciones, de ahí que las analicemos de manera diferenciada.

Siguiendo con la metáfora médica, y con los impresionantes avances en este campo de los últimos años, podemos ver cómo, aunque esté aumentando la esperanza de vida, surgen nuevos problemas sanitarios que antes no existían. Mientras los datos muestran que nunca la humanidad experimentó tantos progresos vivimos una crisis, de envejecimiento o de madurez, que genera ciertos desajustes concentrados en determinadas partes de nuestro cuerpo social.

\section{CRISIS ECONÓMICA Y CRISIS SOCIAL}

En el año 2008 se inicia un periodo continuado de recesión económica que afecta de manera determinante al empleo, al cierre de empresas, así como a la reducción del consumo y la inversión. Lo que comenzó como una crisis financiera con la caída de los grandes bancos inversionistas estadounidenses, como consecuencia de su exposición a las hipotecas subprime, acabó arrastrando a los gobiernos, que consideraron necesario rescatar estas entidades para evitar una crisis mayor, generando con ello una crisis de deuda. La respuesta de los gobiernos ante este trance económico, centrada en fuertes medidas de austeridad, dio origen a amplias contestaciones sociales y a un aumento de la pobreza generalizada en gran cantidad de países del mundo.

Este periodo abarcó desde 2008 hasta 2014, año en el que comezaron a vislumbrarse ciertos visos de mejora en algunos indicadores macroeconómicos. Este sexenio ha quedado ya sellado bajo el marbete de «los años de la crisis» o «la gran recesión». A lo largo de ese tiempo, hubo disparidad en los análisis. Unos consideraron que la salida de la crisis se produciría en forma de $L$ : una primera cauterización de la herida y, luego, estabilizándose la situación en valores post-crisis. Otros llevaban sus apreciaciones al fin del crecimiento progresivo y la llegada de un período de estabilidad de niveles similares a los que existían previos a la crisis. Finalmente, los menos, sostuvieron que la recesión, en el fondo, no era más que un paréntesis en el crecimiento económico que se había vivido durante el siglo anterior, y que se cerraría con una vuelta al desarrollo vivido antes del 2008. Como suele 
suceder, la realidad no tomó al pie de la letra ninguna de las tres teorías, sino que en ella se entremezclaron la segunda y la tercera de las consideraciones anteriores. Desde 2014 observamos cómo los índices van poco a poco escalando hasta los niveles previos a 2008 -claro ejemplo de esto es España, en el que el PIB por habitante ha vuelto a niveles de 2004. Si observamos, abierto el foco todo lo que podamos, otras realidades que quizá nos puedan resultar lejanas, nos damos cuenta de cómo de 2005 hasta 2016, los niveles de pobreza extrema se han ido reduciendo hasta la mitad, a la vez que la esperanza de vida aumentaba en más de tres años. Y es sobre esta base sobre la que creemos poder sostener que, en cualquiera de los escenarios de la crisis, los datos económicos apuntan a una tendencia creciente: vivimos más y vivimos «mejor».

Vivimos más. Basta con tomar los datos que la Organización Mundial (OMS) de la Salud y el Banco Mundial ofrecía relativos a 1960. Uno de cada cinco niños moría antes de cumplir cinco años; hoy sobreviven 19 de cada 20. Junto con esto, la esperanza de vida ha visto prolongarse de manera generalizada, al igual que de manera generalizada se han ido reduciendo las guerras y conflictos armados. Esto nos lleva a considerar desde una perspectiva ciertamente confiada lo que Harari (2015) señala: la violencia retrocede. No podemos eludir, a la hora de considerar esto, que alrededor del 15 por ciento de las muertes durante el siglo XX se producían en sociedades agrícolas, pese al sangrante brío con que unas modernizadas armas se pusieron a prueba en dos guerras mundiales o al empleo taimado que del napalm se hizo en la guerra de Vietnam. Sin embargo, tanto los dos grandes conflictos y el enfrentamiento entre las tropas norteamericanas y la guerrilla del Vietcong, «sólo» provocaron el 5 por ciento de la mortandad total de la centuria. Hoy, la guerra es la causa «sólo» de un 1 por ciento de la mortalidad global.

Podríamos habernos contentado con esto. Hacer nuestro lo que Benavente puso en boca del rey Danisar: «Yo podría ser el último paria de mi reino, un leproso abandonado por todos, sin recuerdo y sin esperanza de goce alguno, y aún quisiera vivir» ${ }^{2}$. Sin embargo, ni parias, ni leprosos, vivimos más y vivimos mejor.

En 1980 todavía el 44\% de las personas eran analfabetas. En medios de medio siglo, el analfabetismo se ha reducido como nunca antes en la Historia: «sólo» el 15 por ciento de las personas no saben ni leer ni escribir. Tal vertiginoso descenso se ha vivido también en los índices de pobreza, que de manera general, se ha reducido en todos los hemisferios del mundo ${ }^{3}$. Una cuarta parte de cuantas personas vivían en los límites más extremos de la

${ }^{2}$ Benavente, Jacinto. Obras completas. VI, Madrid, Aguilar, 1946.

3 Informe del Banco Mundial citado por Sandro Pozzi en El Pais disponible en: https://elpais.com/economia/2015/10/04/actualidad/1443971491_051176.html 
pobreza en la década de los 80 , hoy han salido de ella. China, India y otros países han visto cómo millones de personas han logrado abandonar la supervivencia para poder darse a la vivencia. En el sur de Asia la sufrían el 50\% de las personas; hoy la sufren $15 \%$. En el este de aquel continente y el Pacífico, la situación era aún más lacerante: un $80 \%$ de las personas vivía en la extrema pobreza; es decir: cuatro de cada cinco. Hoy apenas el 3,5\%. En China también han pasado del $90 \%$ al 10\%. En 40 años se ha producido la mayor reducción de la pobreza de la historia. La evolución, la mejora, resulta evidente -aunque no por ser el porcentaje menor que hace unos años, deja de requerir nuestra atención y nuestra acción.

Pero no por evidente está esta dinámica libre de críticas, algunas de ellas bien pertrechadas de argumentos. La más habitual, y la que más argumentos esgrime en su favor, es la que insiste en que este hondo cambio en la economía, junto con el crecimiento, ha aumentado también las diferencias, ahondado en la desigualdad entre unos y otros. Este crecimiento de las desemejanzas, puede observarse al atender a la falta de correlación entre el aumento de la productividad, que en los últimos 50 años se ha disparado hasta multiplicarse en un $200 \%$, y las rentas del trabajo, que no han vivido un incremento ni tan siquiera parecido; antes bien, se han congelado. Algo similar puede verse si fijamos la vista en la pérdida de empleos en algunos sectores, que la Organización Internacional del Trabajo estimó en más de 9 millones en todo el mundo, en un informe previo al final de la crisis (2010); mientras que otro más reciente, elaborado por EY en el año 2015, cifró tal pérdida en 3,8 millones en la eurozona. Pese a esto, y aun a riesgo de que pueda parecer contradictorio, muchos de estos índices globales señalan que el progreso vivido se ha acentuado especialmente en los países pobres, lo que conlleva una reducción global de la desigualdad y sustenta mi afirmación preliminar: vivimos mejor. Ello no quiere decir que las diferencias entre ricos y pobres no sigan siendo en muchos casos abismales; aunque tampoco puede obviarse que incluso en esos índices, que a menudo muestran unos inmensos márgenes de desigualdad, también se estén reduciendo. Al menos, cuatro puntos de 69 a 65 puntos entre 2003 y 2013 (Hellebrandt, Mauro: 2015). Por esto no resulta un gesto onírico anotar aquí lo que ha señalado Norberg (2017): que la desigualdad global ha caído por primera vez en la historia económica.

Tal orden de la situación hace que quede subrayado el hecho de que el crecimiento económico lleva aparejado un aumento de la riqueza de unos, sin condenar a la pobreza a otros (Milanovic, 2012). Es decir: el aumento de la riqueza de unos no se logra a costa de ahondar en la pobreza de otros. Además, más allá de los índices económicos, la generalización de las prestaciones sociales, como la educación y la sanidad, y su mejora continua, nos permiten hablar claramente de una igualdad superior a la de otros tiempos. Pero para ser completamente fieles a la realidad, deberíamos añadir que a ese 
retroceso de la pobreza, a ese aumento de la riqueza en países pobres, a esa salida de millones de personas de extremos paupérrimos, hay que añadirle una tendencia desarrollada en países ricos como Estados Unidos, Alemania, Suecia o España; una tendencia hacia la concentración de la riqueza nacional $\mathrm{y}$ al aumento de las diferencias.

Ante la contemplación de esta escena global, al considerar los datos, podríamos concluir, por muy paradójico que pueda resultar, que en términos absolutos no es la desigualdad en sí lo que genera malestar social, sino su percepción. Y es por esto por lo que podemos decir que las consecuencias más graves de la crisis económica son las que afectan a la sociedad e inciden en sus creencias básicas, especialmente en su confianza y sus perspectivas de futuro.

Y aunque autores como Pinker (2018), en base a lo que hemos visto hasta aquí, remarcan la reducción global de la desigualdad y preconizan la concentración de esfuerzos y atenciones en la reducción de la pobreza, la realidad es que la percepción social de la desigualdad está generando consecuencias y afectaciones en la vida política y en la valoración de la democracia. Porque argumentos como los que esgrime Pinker adolecen de perspectiva; lo hacen por no tener en cuenta aspectos esenciales del comportamiento humano que, sin responder a un patrón racional, tienen un gran impacto social. Algo que como nos indican Guemes y Brugué (2017), desde Myrdal, North, Sen o Stiglitz, se está superando incluso entre los mismos economistas, que están ya incluyendo en sus análisis los factores no económicos. Y es que la reacción social que genera la desigualdad no tendría que ver tanto con un frío cálculo material de índices macroeconómicos, sino con una profunda sensación de injusticia.

Aunque las causas no se reducen a esto. Contribuye a tal sensación el despliegue de una visión a corto plazo que ha acabado por generar una falta de perspectiva, centrada en el presente, dejando a un lado los elementos que ofrecen una visión más amplia de una situación que, como hemos visto y a pesar del bache, como otros ya vividos en el siglo anterior, puede considerarse de progresión sostenida.

«El pasado es un prólogo», escribió Shakespeare. No leerlo, no recordarlo, perder conciencia de que existió y de que de una forma o de otra nos ha configurado, acaba llevando a desarraigar el presente y a desvestir la realidad de unidad, de trama. Una pérdida que no es en abstracto, sino que se vuelve concreta cuando se extravía el sentido y la dirección de los actos propios; cuando por ella, se acaba claudicando del afán de proyectarse hacia el futuro, personal, social y político, sepultando todo tiempo y toda visión que no sea la del hoy inmediato. Y si la realidad es un "ya» palpitante, a duras penas puede mantenerse una visión global, dotada de perspectiva histórica, capaz de sobrevivir al constante goteo de noticias negativas, cuando no escabrosas, que subrayan la anormalidad hasta alzarla, paradójicamente, hasta el 
púlpito de lo cotidiano, aunque tal ascenso en nada se adecue con la realidad estadística. Ante lo cual, la reacción tampoco puede ser una visión nostálgica del pasado, que tiende a idealizarlo, contribuyendo, igualmente, a consolidar percepciones que no se corresponden con los datos. Para muestra, un botón: un estudio del Instituto Motivaction señala el $87 \%$ de la población mundial cree que, pese a los datos ya señalados, en los últimos 20 años, la pobreza global ha permanecido igual o ha empeorado ${ }^{4}$.

A esto, hemos de añadir otra realidad que, a nuestro juicio, no puede ser olvidada: el acceso a la información. Su generalización ha transformado la sociedad, permutándola hacia visiones más críticas y menos tolerantes frente a los errores e injusticias del sistema. De hecho, ya hay quienes señalan entre las causas de que tales percepciones se generalicen, la incapacidad de respuesta ante los cambios tan profundos que la disrupción tecnológica en el ámbito de las TIC ha generado. Entre quienes ya lo han hecho está Manuel Castells (2006), sociólogo referencia en el mundo de la sociedad de la información y en el impacto de la tecnología en la sociedad, que lo hacía de una forma provocadora: «La revolución tecnológica centrada en torno a la información ha trasformado nuestro modo de pensar, de producir, de consumir, de comerciar, de gestionar, de comunicar, de vivir, de hacer la guerra y de hacer el amor». De manera bastante gráfica, pone de manifiesto hasta qué punto la sociedad está cambiando la forma de percibir la realidad y sus valores.

Existe un desajuste entre lo material y lo simbólico. Mientras que lo material -el sistema económico y político- avanza con paso flemático, lo simbólico -la cultura de la sociedad- lo hace con vértigo. Pero tal desbarajuste podría ser asumible, si no se le sumaran las dificultades de lo material, no ya para adaptarse, sino para alcanzar cierto entendimiento con lo simbólico. Así, la incertidumbre, el pesimismo y el miedo aumentan, hasta parecer que se firmara el epitafio de la teoría del progreso eterno y en gran medida del «sueño americano»y con esto, la sensación, que los hechos no corroboran, de que las cosas son peor que hace 50 años pero mejor que en el futuro. Ante lo cual, no cabe sorpresa si el miedo al fracaso avanza con pasos de gigante.

El Papa Francisco ha fijado un marbete para esta percepción generalizada: «la época de la desconfianza», que no existe de manera solitaria, sino que lo hace acompañada de una caída de la «esperanza firme que se tiene de alguien o algo». La desconfianza se convierte así en el indicador principal de la crisis social y alimenta estados de desidia y dispersión.

Esta confianza en el plano simbólico se asociaría a elementos como el optimismo, la satisfacción con la vida o a cómo se visualiza el futuro. Hoy,

${ }^{4}$ Mencionado por Kiko Llaneras en Las Paradojas del Progreso: Datos para el optimismo. disponible en: https:/elpais.com/internacional/2016/12/29/actualidad/14830203 28_085937.html 
cuando la Organización para la Cooperación y el Desarrollo Económico (OCDE) pregunta qué se considera una vida mejor, las respuestas tienen muy poco que ver con las que se daban hace 15 años. Hablamos de elementos como el ingreso familiar disponible, la brecha entre ricos y pobres, el empleo remunerado, las horas de trabajo al año, el nivel educativo, la equidad escolar, la esperanza de vida, la confianza social y la confianza política. Los valores sociales, lo que la sociedad pide al Estado y lo que la sociedad se pide a sí misma están cambiando de una manera rápida, y las instituciones y la economía no están siendo capaces de dar una respuesta. Ahí está el gran reto, porque los términos de efectividad con los que habitualmente pensábamos que se medía el trabajo de los gobiernos pasan a ser medidos por otros parámetros.

Este malestar tiene consecuencias políticas. Si el mundo va a peor para mejorarlo será necesario un cambio de los actores políticos o incluso del sistema. De ahí que junto a esta crisis de confianza simbólica se produzca una crisis en el plano racional, centrada en los lazos entre grupos y personas -confianza social-o en las organizaciones, -confianza institucional- El problema es que ambas se suelen presentar de manera conjunta y sin una distinción clara de tal modo que unas expectativas no realizadas acaban provocando una falta de confianza en las organizaciones y las instituciones, la política y la democracia.

\section{CRISIS POLÍTICA Y CRISIS INSTITUCIONAL}

La crisis política no es tanto una pérdida de relevancia -eso sería una crisis más manejable-, sino algo más profundo: una pérdida de confianza. La crisis de confianza simbólica, marcada con un fuerte componente antielitista, afecta directamente a la política y tras la política, y por un efecto contagio o dominó, la confianza institucional acaba por resentirse, cuando menos.

En lo que se refiere a los políticos, esta quiebra de la certidumbre, tiene consecuencias claras en el plano electoral: ante la rotura de expectativas puestas en los políticos, aumenta el voto a partidos antisistema, que aprovechando el clima de crisis económica y social, señalan a la clase política, rotulándola como la causante y la culpable de la situación y se postulan como solución alternativa, naciente del rechazo a todo lo anterior. Algo que algunos analistas denominan «los bárbaros en las puertas de la ciudad» y que José Jiménez Lozano describió con maestría literaria 5 .

Entendemos la confianza en las instituciones como la creencia del ciudadano acerca de que las instituciones políticas cumplen su función correctamente. De

5 Jiménez Lozano, J. Los comedores de higos. 4/4/2004. ABC Disponible en: http:// www.abc.es/hemeroteca/historico-04-04-2004/abc/Opinion/los-comedores-de-higos_962802893176.html 
este modo la confianza sería el resultado de la concepción de cada institución como digna, creíble, competente, transparente y eficiente (Levi y Stoker 2000). Mientras que la desconfianza sería la percepción de que las instituciones no cumplen debidamente con su papel, lo cual hace que aparezcan como poco creíbles y poco competentes, opacas y no eficientes. Y es esta la percepción que ha ido aumentando consistentemente entre los ciudadanos de las democracias occidentales (Pharr et al., 2000; Newton, 2006; Torcal, 2014), es una pieza clave del funcionamiento del sistema político ya que, como nos recuerdan Guemes y Brugué (2017):

«La confianza en las instituciones de gobierno constituye una medida de apoyo difuso al sistema (Easton, 2006), que favorecen un mayor cumplimiento voluntario de la ley, pago de impuestos y un refuerzo de la legitimidad y los valores del sistema democrático; robustece la capacidad de los gobiernos de diseñar e implementar eficazmente la legislación y las políticas públicas, lo que repercute en un mejor diseño y una mayor eficacia de las políticas públicas (Evans, 1996, 2003; Levi y Stoker, 2000); favorece un mayor activismo o involucramiento en formas de participación política (membresía en partidos, sindicatos y gremios empresarios) y cívica (participación en asociaciones voluntarias convencionales), reforzando las responsabilidades ciudadanas (Norris, 1999); y favorece la adopción de reformas, sobre todo estructurales, cuyos beneficios solo se verán a largo plazo, y es fundamental en situaciones críticas, como los desastres naturales y las crisis económicas o políticas (OCDE, 2013).»

A esto se unen dos dinámicas crecientes: el aumento de demandas materiales de la sociedad, que asumiendo como natural la obligación del Estado de proveer las necesidades básicas de los ciudadanos, ha ido aumentando sus exigencias y el cuestionamiento de la capacidad del Estado para ser el intérprete solitario del interés general. La sociedad reclama. Y en su reclamación exige jugar un papel en la interpretación del interés general, a lo que contribuye, además, la disolución de las jerarquías y que el micropoder del que habla Moisés Naím (2013), específicamente el micropoder político, no tiene suficiente fuerza para sacar adelante sus proyectos por sí sólo. Esto supone un cambio esencial, y en cierta manera paradójico, porque al tiempo que se han asumido las obligaciones del Estado cada vez más exigentes, se va abriendo paso la idea de que el bien común es responsabilidad de todos.

En este cambio, el bien común deja de ser algo que el Estado nos tiene que dar, y ante el cual nosotros somos meros consumidores de servicios proporcionados, para convertirnos en participes de algo que es responsabilidad de todos, y que entre todos tenemos que construir. El cómo es lo de menos. Ya se verá si es a través de servicios, de ayuda, de una serie de plataformas de colaboración público-privada o a través, incluso, de que empresas privadas o asociaciones de la sociedad civil asuman responsabilidades que 
tradicionalmente estaban en lo público. De una forma u otra, la sociedad asume el bien común como responsabilidad de todos.

Y esta asunción de un valor tal como el bien común, tiene su traducción en el Estado, en concreto, en tres principios básicos que el presidente Obama consagró en 2009 en el «Memorándum de Transparencia y Gobierno Abierto»: la transparencia, la colaboración y la participación.

La eficiencia deja de ser la exigencia principal hacia las organizaciones: nuevas demandas de mejor gobernanza van surgiendo. La sociedad pide a las entidades que sean capaces de gestionar sus asuntos económicos, políticos y sociales de una manera ejemplar, no sólo eficaz. Además estas reclamaciones se hacen extensivas a las empresas privadas, obligadas a asumir políticas de transparencia, de relación con accionistas y empleados o con el resto de la sociedad, a través de sus políticas de responsabilidad social corporativa. La gobernanza ha dejado de ser un elemento público para convertirse en un elemento que afecta a cualquier institución que desempeña su labor en la sociedad.

El Estado de bienestar es sustituido por la sociedad de bienestar, como evolución del mismo, en el que ningún actor puede alcanzar por sí solo sus objetivos. Las políticas públicas, en general, no son desempeñadas en exclusiva por el Estado, sino por una red de actores, donde el bien común es una zona gris que se va agrandando y las empresas y la sociedad civil adoptan y van asumiendo cada vez más responsabilidades.

Esta situación de crisis afecta a los actores políticos, ciudadanos, organizaciones políticas e instituciones. Si tuviéramos que anticipar los elementos característicos de la ciudadanía actual podríamos referirnos a su carácter activo y netamente político, una combinación desigual entre la propuesta y la protesta compatible con un ánimo de cambio en el status quo, un componente transversal tecnológico, que afecta de manera determinante a las formas de acción política y a su impacto social, y un componente cosmopolita, de respuesta a problemas de relevancia global, empezando por el ámbito local.

Además, su sociabilidad, siguiendo la lógica de las redes sociales, tiene su base en el individualismo, especialmente entre los más jóvenes -la generación yo- que ha cambiado su forma de relacionarse con los demás, en la que la autorrealización, la solidaridad y acción social para sentirnos mejor y que se vea, se ha convertido en el principal incentivo de participación política. La promesa de pertenecer ha sido sustituida por la promesa de ser conocido - no comprendido, no necesariamente ni siquiera valorado-, pero simplemente reconocido y visto. La imagen cuenta más que lo que hacemos y queremos alcanzar muchos hitos sin esfuerzo. Este individualismo peca de falta de empatía, y se aferra a la retórica de los derechos (derecho a casi todo), mientras se resisten a asumir sus responsabilidades, fomentando una cultura de agravio permanente. 
Poco amigo del compromiso a largo plazo su compromiso social se articula en torno a la consecución de objetivos concretos, que se pueden defender de una forma sencilla, uniéndose a otros para lograrlo y con herramientas para hacerlo al alcance de su mano.

Desde el punto de vista informativo, se alimenta de una información que ha dejado de ser un bien escaso para convertirse en un bien de consumo sobreabundante, al que nos encontramos expuestos a través de la publicidad, internet y la televisión. Hoy sobra la información, lo que hace imperativo organizarla para que sea útil y productiva y facilite el diálogo y la colaboración en la elaboración, aprobación e implementación de la política, evitando las mentiras, la verdad a la carta, y tratando de limitar el sesgo de emisores y receptores ${ }^{6}$. El exceso informativo genera una necesidad por la novedad, por la última noticia, que los medios tratan de satisfacer, en pro de aumentar su audiencia lo que provoca que la información se emita y se consuma fundamentalmente en el corto plazo, y muchas veces sin contrastar. Esto fomenta la superficialidad y la simplificación de problemas complejos, en el debate político.

Esta dependencia de lo inmediato, en lo político, vuelve al ciudadano vulnerable, a pesar del acceso ilimitado a la información, y mucho más influenciable por la presión de un enjambre digital que amenaza la independencia de juicio y provoca un efecto rebaño que disuade las voces u opiniones disidentes.

La nueva política no entiende la política como algo puramente racional sino que cuenta activamente con los afectos. Existe una tendencia a la exaltación del sentimiento, desarrollado una tendencia a la acción sin pensamiento, con gran osadía y sin medir las consecuencias. «Una nueva forma de «saber» no tanto basada en procesos de razonamiento y discusión pública/ científica rigurosa y ordenada, sino de propagación y réplica de «hechos» afines a causas ideológicas e intereses concretos.» (Lynch:2016), disfrutando, como apuntaba JF Kennedy del confort de la propia opinión sin las incomodidades del pensamiento ${ }^{7}$.

Paradójicamente el narcisismo político, permanentemente pendiente de la opinión de los demás, no acepta como legítimas sus opiniones ${ }^{8}$. Y, en ese contexto, un argumento distinto no invita al diálogo, a la conversación, entendida como deliberación constructiva sino que fomenta lo que Martínez

${ }^{6}$ Una visión más amplia de este punto puede encontrarse en Rubio, Rafael. Posdemocracia. Revista Telos. Disponible en: https://telos.fundaciontelefonica.com/posdemocracia-posverdad-democracia/

7 JF Kenendy, Yale University Commencement June 11, 1962.

8 Brooks, D. The Unity illusion, TNYT. Disponible en: https://www.nytimes. com/2016/06/10/opinion/the-unity-illusion.html 
Bascuñana ha llamado el narcisismo de la opinión ${ }^{9}$ que entiende la discrepancia en términos personales, y responde aumentando el nivel de agresividad. Además este narcisismo va aumentando con el comportamiento narcisista.

En el plano organizativo también observamos importantes cambios: Frente al «narcótico más poderoso del mundo, la promesa de pertenecer» (Lasn, 1999), el carácter individualista ya mencionado produce la reducción del peso de la identidad, apareciendo organizaciones con identidades colectivas que ponen en cuestión el papel agregador de organizaciones como los partidos políticos, u otras ONGs generalistas basadas en el sentido de pertenencia de sus miembros. Esta capacidad agregadora, que habitualmente tenía una carga ideológica, es sustituida por la consecución de intereses (de carácter local o global), facilitando la multimilitancia, no asociada a una identidad sino a un perfil líquido, en el que caben además diferentes maneras de militar desde el hiperactivista al voyeur. Surgen así comunidades de acción política informal basadas en compromisos políticos personalizado y mediatizado digitalmente.

La reducción de costes de organización, y la disminución de las barreras para la acción política colectiva permiten una mayor flexibilidad de las organizaciones, que pueden adaptarse a las necesidades de sus colaboradores, y desde el respeto a sus capacidades y a la autonomía individual, pueden centrar sus esfuerzos en potenciar estas capacidades individuales a través de incentivos e instrumentos de coordinación, lejos de los mecanismos de control o sanción habituales en las organizaciones tradicionales.

Estas circunstancias modifican el papel de las organizaciones tradicionales que pasan de ser organizaciones con una identidad fuerte, basadas en el sentido de pertenencia, y con una estructura jerárquica a organizaciones plataforma $(h u b)$ de las comunidades de intereses, escenarios donde los individuos construyen sus experiencias colectivas. Sus prioridades organizacionales cambian centrándose en definir los objetivos, aportar coordinación y motivación, ofrecer herramientas que hagan más útil y eficaz el trabajo de sus miembros... (Benkler, 2011). La organización se construye como una comunidad con la colaboración indispensable de la tecnología.

El activismo exige construcción colectiva pero las organizaciones políticas son cada vez más líquidas y se construyen de relaciones de compromiso variable, lejos de estructuras estables, renovándose y reconformándose a diario como organización política o movimiento en función de las actividades de sus miembros, con la dificultad de mantener entidades con elementos comunes que vayan más allá de la suma de las acciones aisladas de los actores involucrados

${ }_{9}$ Martínez Bascuñan, M. Redes antiliberales. El Pais. Disponible en: https://elpais. com/elpais/2016/10/07/opinion/1475862048_692704.html 
Estos cambios en la organización política pueden tener consecuencias en el actual sistema representativo y en los mecanismos formales de participación, estructurados en torno a organizaciones consolidadas y en los que es difícil introducir organizaciones líquidas que en ocasiones carecen incluso de personalidad jurídica. Frente a lo que pudiera parecer la acción política se convierte en un concepto muy exigente, y sólo para minorías políticamente activas. Mientras que la inmensa mayoría se moviliza solo en situaciones de excepcionalidad, volviendo a la pasividad una vez normalizada la circunstancia que provocó la movilización.

El neoactivismo, convertido en un movimiento pulsional intenso, basado en actividades concretas, y banderas de intereses específicas que carecen de modelo e ideología y se retroalimentan, provoca la fragmentación de las políticas públicas, y su consiguiente polarización, con la dificultad añadida para definir el bien común. Además se corre el peligro de sobrerepresentar a las minorías movilizadas frente a las mayorías silenciosas, que suelen presentar posiciones más extremas provocando que grupos con menos capacidad o acceso no puedan defender sus intereses y posiciones. Otro riego es el de la desafección hacia la sociedad civil tradicional, representada por ONGs, sindicatos, colegios profesionales, que, como consecuencia de la crisis de intermediación, están teniendo dificultades para ofrecer alternativas y poder mantener ese capital social imprescindible para la supervivencia de un estado democrático.

Estos cambios afectan también a la vida política, propiciando políticos de la posverdad. Estos «post-truth politicians $\rangle^{10}$ parecen observar con perplejidad la crisis y ofrecen sus respuestas en función de los diversos planos de la misma en función de su propio posicionamiento político, pero muestran, por lo general, cierta incapacidad para entender el problema. Además operan dentro de una realidad paralela retroalimentada por las redes sociales y unos medios de comunicación disminuidos debido a la fragmentación de la conversación y una situación económica inestable, que les terminan convirtiendo -pensamos que involuntariamente- en extensiones de un reality, o de un programa del corazón.

Esto provoca una desilusión inicial que se traduce en una desconfianza sistemática hacia la política, que, salvo contadas excepciones, afecta casi por igual a políticos, partidos e instituciones democráticas. Todo esto termina generando la decepción con el sistema representativo. Como señalaba Sartori: «las instituciones representativas nos decepcionan, sin duda; pero estos fallos son en gran medida reflejo de nuestro propio desconocimiento de lo

10 Jonathan Freedland. Don't call it post-truth. There's a simpler word: lies. The Guardian Disponible en: https://www.theguardian.com/commentisfree/2016/dec/16/notpost-truth-simpler-words-lies-aleppo-trump-mainstream 
que la representación debe y puede hacer y, en contraposición, no puede hacer» (1999, pág. 2).

En este contexto surgen políticos que hacen de la antipolítica su seña de identidad, y adoptan estrategias de conquista del poder, basadas en aprovechar estas crisis, en sus distintos planos, para alimentar la desconfianza y dividir la sociedad entre la gente «normal» y unas élites que habrían monopolizado política, negocios, cultura.... Adoptando un discurso que contagia a otras fuerzas políticas, que se siente obligadas a adoptar los mismos mecanismos para mantenerse o alcanzar el poder.

Estas posiciones políticas tienen una serie de componentes antiliberales. Cuestiona la ilustración, la capacidad de alcanzar verdades objetivas y la libertad individual. Cuestiona la legitimidad del sistema de representación, de los procesos que nos llevan a las instituciones y, en el nombre del pueblo y el principio democrático, ponen aún más en peligro la democracia.

Como decía De Vega (2017) la democracia liberal se mueve siempre en el equilibro entre el principio democrático, el poder de la gente, y el principio liberal, la protección de los individuos de la tiranía de la mayoría a través de la división de poderes y el reconocimiento de sus derechos fundamentales. Durante la segunda mitad del siglo XX ambos aspectos han convivido de manera pacífica y fructífera, pero hoy en día, la voluntad popular parece entrar, a menudo, en conflicto con los derechos fundamentales. Los dirigentes políticos tratan de excluir a la gente de decisiones importantes, como la inmigración, en nombre de los derechos, mientras que los populistas no tienen problema en ignorar mandatos constitucionales en nombre de la gente. La política se está convirtiendo en una batalla entre la democracia sin derechos, la democracia iliberal, y el liberalismo antidemocrático, de derechos sin democracia (Mounk, 2018).

Esta batalla está provocando el desgaste de la confianza en las instituciones y en la propia democracia. Con especial énfasis entre los jóvenes. Aunque se pueden señalar causas como las de haber vivido siempre en democracia, que hace valorar lo que se tiene, ante la ausencia de referencias vitales de realidades diferentes en sistemas no democráticos. Tomando la democracia como parte del paisaje, algo que se da por descontado, no como conquista que corre el peligro de devaluarse hasta ser considerado superfluo.

\section{LA REFORMA CONSTITUCIONAL Y OTRAS RESPUESTAS A LAS CRISIS}

Ante la percepción generalizada de crisis, y la interrelación entre sus distintos planos, se plantea la hipótesis de una crisis de origen únicamente económica, con una réplica o traslado al ámbito social y político. Si esto fuera así, si bastaría resolver los problemas económicos para resolver también sus efectos sociales y políticos. 
Los que así lo entienden abogan por entender la situación económica como base del problema y plantear una batería de soluciones económicas centradas en la reducción de la desigualdad, como aumentar la inversión en educación, la transformación de las fuentes de ingreso del estado a través de, por ejemplo, su participación en fondos soberanos de inversión, así como de los mecanismos de gasto y redistribución, reequilibrando el impuesto sobre trabajo y sobre el capital, mecanismos de renta básica, transferencias condicionales o impuestos negativos e incluso la transformación del papel, y los valores, del sector privado, limitando el control de determinados sectores y repensando el rol social de las empresas. Estos asumen que el final del malestar económico de una parte importante de la población traerá consigo el fin del malestar también en los planos social, político y democrático.

Por otro lado están aquellos que señalan que cada plano requiere de soluciones diferentes, y que soluciones económicas no llevan necesariamente a un fortalecimiento de la democracia, como se puede observar en un número creciente de países en los que la libertad de mercado, y sus buenos resultados conviven con regímenes autoritarios.

En lo social el acento se pone en un nuevo contrato social, con especial énfasis en salvar la brecha generacional y, en algunos lugares, la brecha territorial y una recuperación de la confianza interpersonal que, como señala Javier Gomá, no se puede imponer por Decreto sino que es necesario ir recuperando, por vías como la ejemplaridad, los valores cívicos y la educación.

En lo político se ensayan ya distintas soluciones. Los liderazgos políticos de jóvenes, el protagonismo electoral de los «no partidos», ya sea con forma de movimientos sociales o candidaturas independientes, y la deriva de la ciudadanía comprometida hacia vías informales de participación política. De fondo dos principios comunes, la obligatoriedad de la transparencia y el principio de que allá donde haya un punto de decisión debe haber un ámbito de negociación.

Llegamos así al plano institucional, de la democracia, donde vamos a detenernos. Se habla con frecuencia de la necesidad de un nuevo contrato político, que allí donde se produzca debería plasmarse en un proceso constituyente $\mathrm{o}$, al menos, en una reforma en profundidad de la Constitución.

Esta vía, que en nuestra opinión sobrevalora la capacidad del derecho y la Constitución para solucionar problemas no necesariamente jurídicos, corre el peligro de cargar sobre el sistema democrático todas las responsabilidades, y de crear una expectativa, similar a aquella que crean los que plantean que el final de la crisis económica supondrá el fin de las crisis sociales, políticas e institucional, pero poniendo todas las expectativas en la reforma de la democracia. Frente a esto ya advertía hace años Giovanni Sartori al apuntar que la democracia tiene un problema de expectativas (Sartori, 1999), y si cargamos sobre los hombros de la democracia la responsabilidad, por ejemplo, de 
hacernos ricos, terminaremos introduciendo la democracia en una profunda crisis.

No conviene generar falsas expectativas con la Constitución y su reforma. Así se está creando un falso problema y una ilusión falsa. Que la Constitución es la raíz del problema y de que su reforma provocará la solución de todos nuestros problemas. Se está poniendo la Constitución como solución a todos los problemas, lo que implícitamente supone señalarla como causa de todos los males. No se pueden crear falsas expectativas porque los problemas económicos, sociales no son problemas constitucionales. Cargar a la Constitución con problemas que deben tener su solución en los consensos políticos es una forma nada recomendable de someter al texto constitucional a tensiones innecesarias.

Esto puede acentuarse al introducir la reforma en el debate electoral, convirtiendo la Constitución en una cuestión partidista, para enarbolarla como estandarte de opciones políticas poco consolidadas. No se trata de eludir el debate público, imprescindible en democracia, y especialmente en cualquier proceso de elaboración o de reforma de la Constitución, sino de enmarcarlo en su contexto, el de la creación o reforma de una norma básica que requiere de un consenso mayoritario, similar al menos al del texto anterior. No se trata sólo de un principio básico de la teoría jurídico política sino de una experiencia práctica, de la que en España tenemos cierta experiencia: la Constitución para ser viable no puede ser una Constitución de partido. Ese fue precisamente el error de nuestro S.XIX: las constituciones de partido. La experiencia reciente nos muestra también que desde el punto de vista de la reforma, convertir la reforma constitucional en parte del debate político, especialmente del debate electoral, puede tener resultados contraproducente dificultando el diálogo, y el consenso necesario para que esta se produzca.

Plantear la reforma Constitucional como una solución a problemas que no tienen su raíz en la Constitución, tiene el riesgo de aumentar el malestar económico, social y político que pretendía solucionar. Las reformas institucionales, necesarias, no requieren una reformulación integral del sistema democrático. Esta reformulación, apuntada por los partidarios de una reforma en profundidad, debería seguir la regla magistral que apuntaba de Vega cuando señalaba que «La reforma es siempre políticamente conveniente cuando resulta jurídicamente necesaria».

A lo expuesto anteriormente se unirían otros riesgos, como la falta de memoria, «las trampas caritativas de la nostalgia» ${ }^{11}$, y las construcciones ideales, tan habituales en «Nuestra dura historia contemporánea, desde las Cortes de Cádiz, demuestra que las creaciones abstractas, las ilusiones, por

${ }^{11}$ García Márquez, G. El amor en tiempos del cólera. Bruguera, 1985. 
nobles que sean, las actitudes extremosas, los pronunciamientos o imposiciones, los partidismos elevados a dogma, no sólo no conducen a la Democracia, sino que la destruyen» (Fernández Miranda, 1995:365).

Se oyen justificaciones de la reforma como la necesidad de «una constitución que de respuesta a la situación creada por la crisis económica», cuando ningún Estado del mundo ha arreglado su economía en una Constitución, aunque algunos que lo han intentado lo han hecho con resultados de miseria conocidos por todos. La desigualdad no se soluciona constitucionalmente. Otros señalan la obligación de integrar a todos aquellos que no participaron en la aprobación del texto Constitucional, en una lógica peligrosa según la cual aquellos que no participan en la elaboración y aprobación de un texto constitucional estarían menos obligados por el mismo. Olvidando la advertencia hecha por de Vega al señalar que la Constitución supone necesariamente la negación del principio democrático, y sólo eso garantiza su supremacía jurídica.

Lo que está detrás es el concepto que tenemos de la constitución: su valor de norma suprema, su legitimidad en el consenso de todos los españoles... Reformar la Constitución no es necesariamente replantearse las bases de nuestro sistema de convivencia. De hecho el acierto en los procesos de revisión constitucional depende de la conjunción de varios factores:

a) Que respondan a una demanda social y busquen resolver problemas ampliamente reconocidos.

b) Que compartan unos principios básicos en lo esencial desde el principio.

c) Que respeten los procedimientos establecidos que buscan garantizar estos equilibrios.

d) Que sean limitados y prudentes para no alterar el equilibrio del texto constitucional.

e) Que incorpore propuestas rigurosas, maduradas y consecuencia del diálogo de las fuerzas políticas y de la sociedad.

f) Que cuente con un consenso asimilable al que concitó el texto que se quiere reformar sobre el resultado final.

Trabajos por lograr que se den estos factores es ahora tarea prioritaria.

\section{BIBLIOGRAFIA}

Castells, M. La era de la información, 3. Fin de Milenio. Alianza, 2006.

BenkLer, Y. The Penguin and the Leviathan: How Cooperation Triumphs over SelfInterest, Random House, 2011.

De Vega, P. Obras escogidas. CEPC, 2017. 
Fernández Miranda, P., Fernández Miranda, A. Lo que el Rey me ha pedido. Torcuato Fernández Miranda y la Reforma Política, Plaza \& Janes, 1995.

FuKuYAma, F. El fin de la historia y otros ensayos, Alianza, 2015.

Guemes, C., Brugué, Q. Confianza y gobierno abierto en América Latina, en Desde el Gobierno Abierto al Estado Abierto en América Latina y el Caribe, CEPAL, 2017.

Harari, Y. N. Sapiens (De animales a Dioses), Debate, 2015.

Hellebrandt, T.; Mauro, P. The Future of Worldwide Income Distribution, Working paper, Peterson Institute for International Economics, 2015.

LASN, K. Culture Jam, HarperCollins, 1999.

LyNCH, M. P. The Internet of Us: Knowing More and Understanding Less in the Age of Big Data. Liveright, 2016.

Milanovic, B. Los que tienen y los que no tienen: Breve historia y particular historia de la desigualdad global. Alianza, 2012.

Mounk, Y. The People vs Democracy: Why Our Freedom is in Danger and How to Save It. Harvard University Press; 2018.

NAIM, M. El fin del poder. Debate, 2013.

Norberg, J. Progreso: 10 razones para mirar al futuro con optimismo. Planeta, 2017.

PINKER, S. Enlightenment Now, Penguin, 2018.

SARTORI, G. En defensa de la representación política. Claves de la razón práctica, n. ${ }^{\circ} 91,1999$. 